\title{
Impact of Dietary Intervention on Serum Neurofilament Light Chain in Multiple Sclerosis
}

Markus Bock, MD, Falk Steffen, MD, Frauke Zipp, MD, and Stefan Bittner, MD

Neurol Neuroimmunol Neuroinflamm 2022;9:e1102. doi:10.1212/NXI.0000000000001102
Correspondence

Dr. Bock

markus.bock@posteo.de

\section{Abstract}

\section{Background and Objectives}

Adapted ketogenic diet (AKD) and caloric restriction (CR) have been suggested as alternative therapeutic strategies for multiple sclerosis (MS), but information on their impact on neuroaxonal damage is lacking. Thus, we explored the impact of diets on serum neurofilament light chain (sNfL) levels in patients with relapsing-remitting MS.

\section{Methods}

We retrospectively evaluated a prospective randomized controlled trial of 60 patients with MS who were on a common diet or ketogenic diet or fasting. We examined sNfL levels of 40 participants at baseline and at the end of the study after 6 months using single molecule array assay.

\section{Results}

sNfL levels were investigated in 9 controls, 14 participants on CR, and 17 participants on AKD. Correlation analysis showed an association of sNfL with age and disease duration; an association was also found between sNfL and the Multiple Sclerosis Functional Composite. AKD significantly reduced sNfL levels at 6 months compared with the common diet group ( $p=$ $0.001)$.

\section{Discussion}

For clinical or study use, consider that AKD may incline sNfL levels independent of relapse activity up to 3 months after initiation. At 6 months, AKD, which complements current therapies, reduced sNfL levels, therefore suggesting potential neuroprotective effects in MS. A single cycle of seven-day fasting did not affect sNfL. AKD may be an addition to the armamentarium to help clinicians support patients with MS in a personalized manner with tailored diet strategies.

\section{Trial Registration Information}

Clinical trial registration number NCT01538355.

\footnotetext{
From the Department of Neurology (M.B., F.S., F.Z., S.B.), Focus Program Translational Neuroscience (FTN) and Immunotherapy (FZI), Rhine Main Neuroscience Network (rmn2), University Medical Center of the Johannes Gutenberg University Mainz; Institute of Biochemistry (M.B.), University Medicine Berlin-Charité, Germany; and Experimental \& Clinical Research Center (ECRC) A Joint Cooperation of Charité Medical Faculty and Max-Delbrueck-Center for Molecular Medicine (MDC) (M.B.). 


\section{Glossary}

$\mathbf{A K D}=$ adapted ketogenic diet; $\mathbf{B M I}=$ body mass index; $\mathbf{C D}=$ common diet; $\mathbf{C R}=$ caloric restriction; $\mathbf{D M T}=$ diseasemodifying therapy; MS = multiple sclerosis; MSFC = Multiple Sclerosis Functional Composite; PASAT = Paced Auditory Serial Addition Test; $\mathbf{S i M o A}=$ single molecule assay; $\mathbf{s N f L}=$ serum neurofilament light chain.

In multiple sclerosis (MS), effective therapeutic strategies and sensitive biomarkers to evaluate drug efficacy and disease course are urgently needed. Serum neurofilament light chain protein (sNfL) has recently been suggested as a promising candidate for a reliable, easy-to-use biomarker of neuroaxonal damage that accurately detects changes over both long and short time intervals in MS. ${ }^{1,2}$ After axonal injury, NfL is elevated in both the CSF and in the peripheral blood, where it can be measured by highly sensitive single molecule assays (SiMoA) ${ }^{3,4}$ Studies have suggested a possible role of caloric restriction (CR) and adapted ketogenic diet (AKD) on neuroinflammation in MS and other neurologic disorders. ${ }^{5-7}$ The observed diet-induced improvement of neuronal resistance and axonal survival are clearly neuroprotective, but the underlying mechanisms remain elusive. ${ }^{5,8}$ In the present study, we investigated whether $\mathrm{AKD}$ and $\mathrm{CR}$ in comparison to common diet $(\mathrm{CD})$ may affect neurodegeneration as measured by sNfL levels in MS.

\section{Methods}

\section{Clinical Trial Design, Patients, Study Setting, Interventions, and Primary Outcome}

All study details were described previously ${ }^{6,79}$ and are presented in eMethods, links.lww.com/NXI/A653. This study was a threearmed parallel group, single-centered, controlled and randomized clinical trial. This study was registered at clinicaltrials.gov as NCT01538355.

\section{Outcome Measure}

The sNfL concentration of 40 patients was quantified in 2020/ 2021.

\section{sNfL Measurements}

We applied the same method as described recently ${ }^{3}$ and presented in eMethods, links.lww.com/NXI/A653. In brief, sNfL was measured in several rounds by SiMoA HD-1 (Quanterix) using the NF-Light Advantage Kit (Quanterix) from the same batch according to the manufacturer's instructions. sNfL analysis was performed in a blinded fashion without clinical information about patients.

\section{Control Diet}

Patients on CD met the criteria of a common diet in the German population as described in the National Nutrition Survey II (mri.bund.de/de/institute/ernaehrungsverhalten/ publikationen/forschungsprojekte/nvsii/).

\section{Caloric Restriction}

As previously described, a single cycle of 7-day CR (200-350 $\mathrm{kcal} / \mathrm{d}$ ) was performed at study outset; a 3-day stepwise reintroduction to an isocaloric common diet was performed starting on day $8 .^{6}$

\section{Adapted Ketogenic Diet}

Patients followed an AKD for 6 months from study outset. We recommended an average daily intake of $<50 \mathrm{~g}$ carbohydrates, $>160 \mathrm{~g}$ fat (omega 6 vs omega 3 ratio 2:1), and average protein intake $\leq 100 \mathrm{~g}$ per day. Compliance during CR and AKD was monitored via ketosis self-measured in blood and urine.

\section{Standard Protocol Approvals, Registrations, and Patient Consents}

This study was approved by the local ethics committee in the frame of the IGEL study (ethics no. EA1/105/11). All patients included in this study signed specific informed consent.

\section{Statistical Analysis}

We used analyses of covariance to test for group differences using sNfL baseline data, number of clinical relapses over the course of the study, and body mass index (BMI) as covariates. The Wilcoxon matched-pairs signed-rank test analysis was used for intragroup statistics.

\section{Data Availability}

Anonymized data will be made available on request from any qualified investigator.

\section{Results}

\section{Situation Before Dietary Intervention}

\section{Baseline Intergroup Comparison: No Differences in Outcome}

Patient demographics did not differ significantly when the different intervention groups were compared (Table 1). The use of the disease-modifying therapy (DMT) glatiramer acetate was significantly different between the groups, but this is clinically not relevant. sNfL levels did not differ significantly between the 3 groups before dietary interventions. These data indicate that the dietary habits of the patients involved in the study did not influence the sNfL concentration at baseline.

Next, we correlated disease-related and participant-reported parameters across all groups involving all individuals of all experimental groups. We found a significant association between sNfL and age $(r=0.347, p<0.05)$ and disease duration $(r=0.313, p<0.05)$ confirming observations of 
Table 1 Baseline Characteristics and Associations

\begin{tabular}{|c|c|c|c|c|c|c|c|c|c|c|c|c|}
\hline \multicolumn{3}{|c|}{ Baseline characteristics } & \multicolumn{2}{|c|}{$C D(n=9)$} & SD IQR & \multicolumn{2}{|c|}{$C R(n=14)$} & SD IQR & \multicolumn{2}{|c|}{ AKD $(n=17)$} & SD IQR & ${ }^{a} p$ Value \\
\hline \multicolumn{3}{|l|}{ Age, y } & \multicolumn{2}{|l|}{50} & 6 & \multicolumn{2}{|c|}{45.71} & 10.5 & \multicolumn{2}{|l|}{43.06} & 9.7 & 0.3 \\
\hline \multicolumn{3}{|l|}{ Sex, F/M } & \multicolumn{2}{|c|}{$6 / 3(67 / 33)$} & & \multicolumn{2}{|c|}{$12 / 2(86 / 14)$} & & \multicolumn{2}{|c|}{$13 / 4(76 / 24)$} & & 0.6 \\
\hline \multicolumn{3}{|c|}{ Expanded Disability Status Scale score } & \multicolumn{2}{|l|}{3.0} & $1.75-4$ & \multicolumn{2}{|l|}{3.5} & $2.4-4.0$ & \multicolumn{2}{|l|}{3.0} & $2.5-3.5$ & 0.5 \\
\hline \multicolumn{3}{|c|}{ Disease duration, y } & \multicolumn{2}{|l|}{11.0} & 10.3 & \multicolumn{2}{|c|}{10.6} & 7.8 & \multicolumn{2}{|l|}{7.1} & 5.3 & 0.3 \\
\hline \multicolumn{3}{|c|}{ Relapse rate 12 mo prior study outset } & \multicolumn{2}{|l|}{0.22} & 0.4 & \multicolumn{2}{|c|}{0.26} & 0.4 & 0.47 & & 0.5 & 0.3 \\
\hline No immune mo & dulati & g drugs & $1(11)$ & & & $2(1<$ & & & $5(29)$ & & & 0.4 \\
\hline Glatiramer acet & tate & & $7(78)$ & & & $4(25$ & & & $4(24)$ & & & 0.02 \\
\hline Interferon beta & & & 0 & & & $6(43$ & & & $4(24)$ & & & 0.07 \\
\hline Fingolimod & & & 0 & & & $1(7)$ & & & $3(18)$ & & & 0.3 \\
\hline Natalizumab & & & $1(11)$ & & & $1(7)$ & & & $1(6)$ & & & 0.9 \\
\hline BMI, kg/m² & & & 26.6 & & 7.3 & 26.8 & & 4.7 & 26.3 & & 4.9 & 0.7 \\
\hline Percent body fa & & & 36.2 & & 11.3 & 37.1 & & 9.6 & 36.3 & & 9.5 & 0.9 \\
\hline Fasting blood st & ugar, $n$ & Imol/L & 4.6 & & 0.5 & 4.5 & & 0.8 & 4.4 & & 0.5 & 0.9 \\
\hline$\beta$-hydroxybutyr & ate, $\mu \mathrm{r}$ & $\mathrm{nol} / \mathrm{L}$ & 105.9 & & 72.1 & 111. & & 118.3 & 112.4 & & 100.5 & 0.6 \\
\hline MSFC-3 & & & 0.17 & & 0.7 & -0.1 & & 0.7 & -0.02 & & 0.9 & 0.3 \\
\hline MSFC-2 & & & 0.34 & & 0.8 & -0.0 & & 0.6 & -0.14 & & 0.9 & 0.05 \\
\hline PASAT-3 & & & 49.56 & & 11.3 & 40.5 & & 12.5 & 46.79 & & 10 & 0.09 \\
\hline $\mathrm{sNfL}, \mathrm{ng} / \mathrm{mL}$ & & & 8.9 & & 3.6 & 10.3 & & 3.6 & 8.5 & & 2.0 & 0.3 \\
\hline Associations & Age & Disease Duration & PASAT-3 & MSFC-3 & MSFC-2 & BMI & EDSS score & MS-54 PH & MS-54 MH & FSS score & MFIS score & e BDI \\
\hline sNfL & & & & & & & & & & & & \\
\hline Spearman rho & 0.347 & 0.313 & -0.406 & -0.317 & -0.298 & -0.133 & 0.013 & 0.099 & 0.031 & -0.122 & -0.109 & -0.186 \\
\hline$p$ (2 tailed) & 0.01 & 0.02 & 0.004 & 0.03 & 0.04 & 0.41 & 0.93 & 0.55 & 0.84 & 0.41 & 0.47 & 0.22 \\
\hline
\end{tabular}

Abbreviations: $\mathrm{AKD}=$ adapted ketogenic diet; $\mathrm{BMI}=$ body mass index; $\mathrm{CD}=$ common diet; $\mathrm{CR}=$ caloric restriction diet; $\mathrm{MSFC}=$ Multiple Sclerosis Functional Composite; PASAT = Paced Auditory Serial Addition Test; sNfL = serum neurofilament light chain.

Baseline intergroup analysis: data are presented as mean (SD), number (\%), or median (interquartile range, IQR), as appropriate. Baseline data were available for 40 patients.

a Nonparametric Kruskal-Wallis test to compare between all 3 groups.

Abbreviations: BDI = Beck Depression Inventory; BMI = body mass index; EDSS = Expanded Disability Status Scale; FSS = Fatigue Severity Scale; MFIS = Modified Fatigue Impact Scale; MSFC = Multiple Sclerosis Functional Composite; PASAT = Paced Auditory Serial Addition Test; sNfL = serum neurofilament light chain.

Baseline cross-group correlation: Analysis between SNfL and disease-related or subject-reported parameters.

Multiple Sclerosis Quality of Life-54 physical/mental health (MS-54 PH/MH).

Bold indicates significance, defined as $p<0.05$.

other groups. Moreover, we observed a significant inverse correlation between sNfL and the Multiple Sclerosis Functional Composite 2 and 3 (MSFC $2+3)(r=-0.298, p<$ $0.05 ; r=-0.317, p<0.05)$ and the Paced Auditory Serial Addition Test $3(r=-0.298, p<0.005)$ (Table 1; eFigure 1-eFigure 5, links.lww.com/NXI/A653). Of interest, sNfL levels did not significantly correlate with BMI or with the clinically meaningful neurologic measure Expanded Disability Status Scale. There was also no correlation with the self-report questionnaires Multiple Sclerosis Quality of Life-54 (MS-54), Fatigue Severity Scale, Modified Fatigue Impact Scale, and Beck Depression Inventory.

\section{$\mathrm{NfL}$ Alterations as Consequence of Dietary Intervention}

\section{Intragroup Comparison: AKD Induced Significant Reductions in sNfL Within 6 months}

In the AKD group $(n=17)$, we found a significant decrease in the $\mathrm{SNfL}$ level from 8.5 at baseline (no dietary intervention) to $7.1 \mathrm{pg} / \mathrm{mL}$ (mean difference $-1.307 ; 95 \%$ CI -2.256 to $-0.357 ; p<0.05)$ at the end of the study after 6 months. The analysis of the CR group $(\mathrm{n}=14)$ and $\mathrm{CD}$ group $(\mathrm{n}=9)$ showed similar sNfL levels at baseline and at the final visit (Figure 1 and eTable 1, links.lww.com/NXI/A653). 


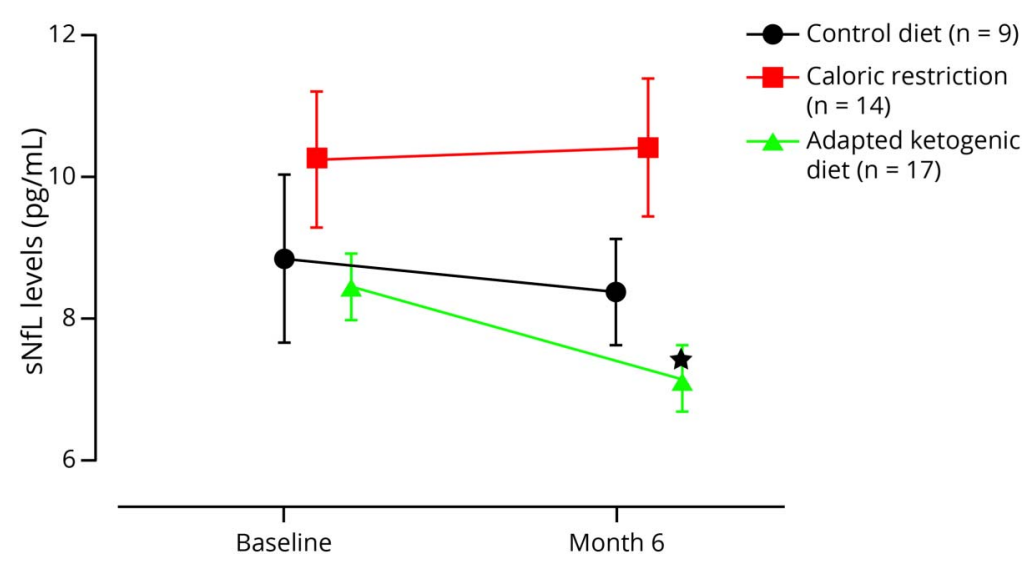

Alterations of serum neurofilament light chain (sNfL) levels induced by caloric restriction and adapted ketogenic diet. Data represent mean \pm standard error of the mean and were measured at baseline and retested at 6 months for all groups. $p$ values indicate Wilcoxon matched-pairs signed rank test analysis, ${ }^{*} p<0.05$

\section{Intergroup Comparison: AKD Lowers sNfL Levels in Comparison to Common Diet}

We used baseline sNfL concentrations, relapse rate, and $\Delta$-BMI as covariates for between-group evaluation. At the end of the study, we observed a significant decline in sNfL levels (Figure 2 and eTable 2, links.lww.com/NXI/A653) when we compared AKD with CD (adjusted difference -2.145 \pm 0.615 ; 95\% CI -3.393 to $-0.897 ; p=0.001$ ) after 6 months. We did not find a difference in sNfL levels between CR and CD groups at month 3 (adjusted difference $1.24 \pm 1.71$; 95\% CI -2.236 to $4.716 ; p=0.682$ ).

\section{Relapse Rate and sNfL Over the Course of the Study}

Twelve months prior study outset, the relapse rate did not differ significantly between the groups (Table 1). In the course of the study, 3 relapses in the CD group, 2 relapses in the $\mathrm{CR}$ group, and 1 relapse in the $\mathrm{AKD}$ group were reported. When analyzing sNfL levels at month 3 , we detected a significant increase over all groups (eFigure 6 and eTable 1, links.lww.com/NXI/A653). After excluding samples from patients with relapse activity, the sNfL levels of the $\mathrm{AKD}$ group remained elevated (eFigure 7, links.lww. com/NXI/A653).

\section{Discussion}

In this randomized controlled trial we investigated the impact of intermittent fasting/CR and $\mathrm{AKD}$ on sNfL levels in patients with MS. In the examined groups, sNfL levels were comparable with previous studies using the same methodology supporting the reliability of our results and of the applied assay analysis method. ${ }^{3}$ However, earlier studies have described higher sNfL levels due to various internal protocols, as recently discussed. ${ }^{10}$

This setting not only allowed assessment of the relative effects of AKD treatment vs common diet and 7-day fasting in a parallel randomized design but also provided the opportunity to study the relation of $\mathrm{sNfL}$ as a specific marker of neuroaxonal damage with other anthropometric, clinical, and

Figure 2 Comparison of sNfL Levels in Patients With MS on Adapted Ketogenic Diet With Common Diet

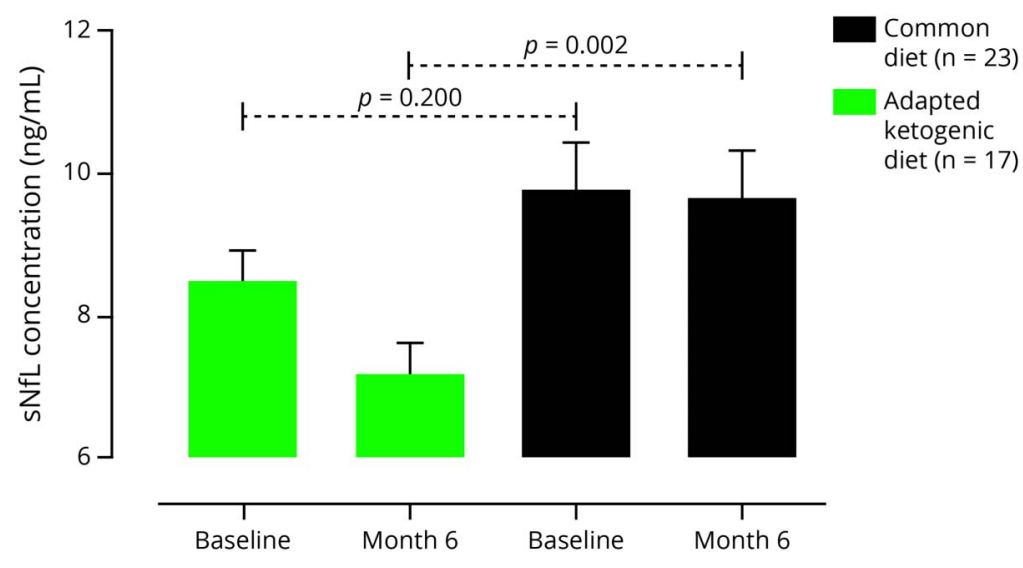

After 6 months of adapted ketogenic diet, the serum neurofilament light chain (sNfL) concentration declined significantly compared to the common diet group. Data were measured at baseline and retested at 6 months. Data represent mean \pm standard error of the mean. ${ }^{\star \star} p<0.01$ analysis of covariance (ANCOVA) adjusted for relapse rate, $\mathrm{BMI}$ and baseline dependencies. 
patient-reported measures of disease activity and severity obtained under good clinical practice conditions.

Baseline characteristics of patients included in this analysis do not suggest any relevant selection bias. $\mathrm{sNfL}$ concentrations in patients were similar over all groups at baseline. sNfL levels at baseline were correlated with functional markers of disease activity (e.g., PASAT and MSFC) confirming recent reports. ${ }^{3}$ Although diet as an environmental factor has been acknowledged in MS, its precise role in the pathogenesis of MS is still far from clear. Moreover, dietary interventions are rapidly gaining popularity within the MS community, but little is known about their safety. AKD and CR have been suggested to induce autophagy and to improve gut microbiota, redox status, and regulatory $\mathrm{T}$ cells in a variety of diseases. $5,7,9,11,12$

It has previously been shown that NfL levels, as a neuroaxonal integrity parameter and marker of treatment response, decrease after initiation of $\mathrm{DMTs}^{3}$ In line with this, our results indicate that AKD may influence sNfL levels in patients with MS. More studies are necessary to evaluate the longitudinal impact of repeated fasting cycles on $\mathrm{sNfL}$ levels in MS.

Our analysis reflects a significant relationship between AKD and declining sNfL levels at 6 months. This suggests that AKD may benefit the course of disease in MS. However, more comprehensive studies with an expanded time span are needed to examine whether effects could relate to the diet itself rather than its impact on MS. The limitations of our study include its short observation time of 6 months, MRI was not performed and a limited power, due to a relatively small number of participants ( $n=40$ analyzed patients). It should also be noted that the extent of variation indicating a clinically meaningful change in longitudinal sNfL measurements has not yet been defined. However, we also found increased sNfL levels in the $\mathrm{AKD}$ group, independent of relapse activity at month 3. Our observation could be due to autophagy of which AKD and CR are strong inductors. ${ }^{11,12}$ Of interest, it was reported that autophagy promotes intracellular degradation of cytoskeleton but also seems to be essential for the survival of neuronal cells. ${ }^{13}$ However, it is likely that release of degradation products would increase sNfL levels extracellularly (and thus in serum) at least in the short term-thus our results would be consistent with the latter results of different groups.

$\mathrm{AKD}$ needs more time than $\mathrm{CR}$ to activate homeostatic processes, e.g., autophagy, due to the process of ketoadaptation and slower/lower ketone body excess. This may explain why we did not detect an increase in sNfL in the CR group at month 3 .

Overall, our study suggests that an AKD offers an avenue to impact sNfL levels, which seems to be a promising biomarker in neuroinflammatory diseases, supporting the use of dietary

interventions as a treatment tool for MS. These findings are of urgent medical interest because such dietetic strategies exhibit few unwanted side effects.

\section{Acknowledgment}

This study was supported by the Deutsche Forschungsgemeinschaft (DFG) (SFB CRC-TR-128 to FZ and SB; CRC1080 to FZ; SFB 1292 to FZ; and the Myelin Projekt e.V.; Familie Ernst Wendt Stiftung Köln; and Dr. Schär AG which were not involved in any decision-making processes relating to the study or its participants. The authors thank Dr. Cheryl Ernest for proofreading and editing the manuscript.

\section{Study Funding}

No targeted funding reported.

\section{Disclosure}

M. Bock, F. Steffen, S, Bittner, and F. Zipp report no disclosures. Go to Neurology.org/NN for full disclosures.

\section{Publication History}

Received by Neurology: Neuroimmunology \& Neuroinflammation April 13, 2021. Accepted in final form September 21, 2021.

\section{Appendix Authors}

\begin{tabular}{|c|c|c|}
\hline Name & Location & Contribution \\
\hline $\begin{array}{l}\text { Markus } \\
\text { Bock, } \\
\text { MD }\end{array}$ & $\begin{array}{l}\text { Department of Neurology, } \\
\text { Focus Program Translational } \\
\text { Neuroscience (FTN) and } \\
\text { Immunotherapy (FZI), Rhine } \\
\text { Main Neuroscience Network } \\
\text { (rmn2), University Medical } \\
\text { Center of the Johannes } \\
\text { Gutenberg University Mainz, } \\
\text { Germany; Institute of } \\
\text { Biochemistry, University } \\
\text { Medicine Berlin, Germany; } \\
\text { Experimental \& Clinical } \\
\text { Research Center (ECRC) A joint } \\
\text { cooperation of Charité Medical } \\
\text { Faculty and Max-Delbrueck- } \\
\text { Center for Molecular Medicine } \\
\text { (MDC) }\end{array}$ & $\begin{array}{l}\text { Drafting/revision of the } \\
\text { manuscript for content, } \\
\text { including medical writing for } \\
\text { content; major role in the } \\
\text { acquisition of data; study } \\
\text { concept or design; and analysis } \\
\text { or interpretation of data }\end{array}$ \\
\hline $\begin{array}{l}\text { Falk } \\
\text { Steffen, } \\
\text { MD }\end{array}$ & $\begin{array}{l}\text { Department of Neurology, } \\
\text { Focus Program Translational } \\
\text { Neuroscience (FTN) and } \\
\text { Immunotherapy (FZI), Rhine } \\
\text { Main Neuroscience Network } \\
\text { (rmn2), University Medical } \\
\text { Center of the Johannes } \\
\text { Gutenberg University Mainz, } \\
\text { Germany }\end{array}$ & $\begin{array}{l}\text { Drafting/revision of the } \\
\text { manuscript for content, } \\
\text { including medical writing for } \\
\text { content; study concept or } \\
\text { design; and analysis or } \\
\text { interpretation of data }\end{array}$ \\
\hline $\begin{array}{l}\text { Frauke } \\
\text { Zipp, } \\
\text { MD }\end{array}$ & $\begin{array}{l}\text { Department of Neurology, } \\
\text { Focus Program Translational } \\
\text { Neuroscience (FTN) and } \\
\text { Immunotherapy (FZI), Rhine } \\
\text { Main Neuroscience Network } \\
\text { (rmn2), University Medical } \\
\text { Center of the Johannes } \\
\text { Gutenberg University Mainz, } \\
\text { Germany }\end{array}$ & $\begin{array}{l}\text { Drafting/revision of the } \\
\text { manuscript for content, } \\
\text { including medical writing for } \\
\text { content; study concept or } \\
\text { design; and analysis or } \\
\text { interpretation of data }\end{array}$ \\
\hline
\end{tabular}


Appendix (continued)

\begin{tabular}{|c|c|c|}
\hline Name & Location & Contribution \\
\hline $\begin{array}{l}\text { Stefan } \\
\text { Bittner, } \\
\text { MD }\end{array}$ & $\begin{array}{l}\text { Department of Neurology, } \\
\text { Focus Program Translational } \\
\text { Neuroscience (FTN) and } \\
\text { Immunotherapy (FZI), Rhine } \\
\text { Main Neuroscience Network } \\
\text { (rmn2), University Medical } \\
\text { Center of the Johannes } \\
\text { Gutenberg University Mainz, } \\
\text { Germany }\end{array}$ & $\begin{array}{l}\text { Drafting/revision of the } \\
\text { manuscript for content, } \\
\text { including medical writing for } \\
\text { content; study concept or } \\
\text { design; and analysis or } \\
\text { interpretation of data }\end{array}$ \\
\hline
\end{tabular}

\section{References}

1. Uphaus T, Bittner S, Gröschel S, et al. NfL (neurofilament light chain) levels as a predictive marker for long-term outcome after ischemic stroke. Stroke. 2019;50(11): 3077-3084.

2. Pape K, Steffen F, Zipp F, Bittner S. Supplementary medication in multiple sclerosis: real-world experience and potential interference with neurofilament light chain measurement. Mult Scler J Exp Transl Clin. 2020;6(3):2055217320936318.

3. Bittner S, Steffen F, Uphaus T, et al. Clinical implications of serum neurofilament in newly diagnosed MS patients: a longitudinal multicentre cohort study. EBioMedicine. 2020;56:102807.
4. Siller N, Kuhle J, Muthuraman M, et al. Serum neurofilament light chain is a biomarker of acute and chronic neuronal damage in early multiple sclerosis. Mult Scler. 2019;25(5):678-686.

5. Kim DY, Hao J, Liu R, Turner G, Shi FD, Rho JM. Inflammation-mediated memory dysfunction and effects of a ketogenic diet in a murine model of multiple sclerosis. PLoS One. 2012;7(5):e35476.

6. Bock M, Karber M, Kuhn H. Ketogenic diets attenuate cyclooxygenase and lipoxygenase gene expression in multiple sclerosis. EBioMedicine. 2018;36:293-303.

7. Choi IY, Piccio L, Childress P, et al. A diet mimicking fasting promotes regeneration and reduces autoimmunity and multiple sclerosis symptoms. Cell Rep. 2016;15(10): 2136-2146.

8. Ni FF, Li CR, Liao JX, et al. The effects of ketogenic diet on the Th17/Treg cells imbalance in patients with intractable childhood epilepsy. Seizure. 2016;38:17-22.

9. Swidsinski A, Dörffel Y, Loening-Baucke V, et al. Reduced mass and diversity of the colonic microbiome in patients with multiple sclerosis and their improvement with ketogenic diet. Front Microbiol. 2017;8:1141.

10. Barro C, Chitnis T, Weiner HL. Blood neurofilament light: a critical review of its application to neurologic disease. Ann Clin Transl Neurol. 2020;7(12): 2508-2523.

11. Wang $\mathrm{BH}, \mathrm{Hou} \mathrm{Q}, \mathrm{Lu} \mathrm{YQ}$, et al. Ketogenic diet attenuates neuronal injury via autophagy and mitochondrial pathways in pentylenetetrazol-kindled seizures. Brain Res. 2018;1678:106-115.

12. Alirezaei M, Kemball CC, Flynn CT, Wood MR, Whitton JL, Kiosses WB. Shortterm fasting induces profound neuronal autophagy. Autophagy. 2010;6(6) 702-710.

13. Chen JX, Sun YJ, Wang P, et al. Induction of autophagy by TOCP in differentiated human neuroblastoma cells lead to degradation of cytoskeletal components and inhibition of neurite outgrowth. Toxicology. 2013;310:92-97. 


\title{
Neurology \\ Neuroimmunology \& Neuroinflammation
}

\author{
Impact of Dietary Intervention on Serum Neurofilament Light Chain in Multiple \\ Sclerosis \\ Markus Bock, Falk Steffen, Frauke Zipp, et al. \\ Neurol Neuroimmunol Neuroinflamm 2022;9; \\ DOI 10.1212/NXI.0000000000001102
}

This information is current as of November 11, 2021

\section{Updated Information \& Services}

References

Subspecialty Collections

Permissions \& Licensing

Reprints including high resolution figures, can be found at:

http://nn.neurology.org/content/9/1/e1102.full.html

This article cites 13 articles, 0 of which you can access for free at: http://nn.neurology.org/content/9/1/e1102.full.html\#\#ref-list-1

This article, along with others on similar topics, appears in the following collection(s):

Class II

http://nn.neurology.org//cgi/collection/class_ii

Clinical trials Randomized controlled (CŌNSORT agreement)

http://nn.neurology.org//cgi/collection/clinical_trials_randomized_cont rolled_consort_agreement

Multiple sclerosis

http://nn.neurology.org//cgi/collection/multiple_sclerosis

Information about reproducing this article in parts (figures,tables) or in its entirety can be found online at:

http://nn.neurology.org/misc/about.xhtml\#permissions

Information about ordering reprints can be found online:

http://nn.neurology.org/misc/addir.xhtml\#reprintsus

Neurol Neuroimmunol Neuroinflamm is an official journal of the American Academy of Neurology.

Published since April 2014, it is an open-access, online-only, continuous publication journal. Copyright

Copyright $\odot 2021$ The Author(s). Published by Wolters Kluwer Health, Inc. on behalf of the American

Academy of Neurology.. All rights reserved. Online ISSN: 2332-7812.

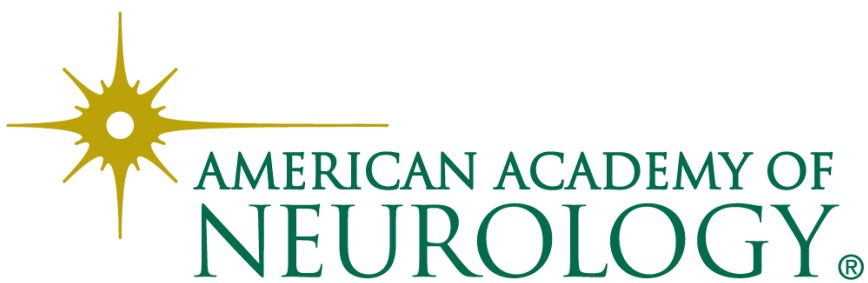

